\title{
Sequential Prefrontal Lobe Volume Changes in Epileptic Patients with Continuous Spikes and Waves During Slow Sleep
}

\author{
Hideaki Kanemura and Masao Aihara \\ Department of Pediatrics, Faculty of Medicine, University of Yamanashi
}

Japan

\section{Introduction}

Epilepsy with continuous spikes and waves during slow sleep (CSWS), which is one of the prototypes of electrical status epilepticus during slow wave sleep (ESES), is a rare disease that affects children and is associated with deterioration of one or more cognitive functions, behavioral disturbances, spike and spike-wave discharges increased during slow wave sleep, and epileptic seizures. The pattern of deficits characteristic of ESES occurs mainly in the first decade of life. Almost all CSWS patients present with seizures (Smith \& Poley, 2008). Seizures are typically nocturnal, partial motor or generalized convulsions (Tassinari et al., 2005).

Although the most prominent feature of epilepsy is seizure, the condition may also involve mental health problems, including hyperactivity, inattention, learning disabilities, other disease-related quality of life impairments, and psychopathology (Noeker et al., 2005). Nearly all investigators have reported a high prevalence of behavioral problems in children with epilepsy. Electroencephalographic monitoring can detect subclinical spike frequency, which may affect attention and other aspects of cognitive functioning in various ways, even in the absence of clinical seizures. Although any attempt to equate epileptiform activity with epilepsy is generally discouraged, the occurrence of a paroxysmal change in cerebral electrical activity simultaneously accompanied by cognitive impairment meets generally accepted definitions of an epileptic seizure. Neuropsychological impairment occurs in almost all cases of CSWS, usually being coincidental with the detection of ESES and representing one of the crucial signs of the syndrome (Tassinari et al., 2005). CSWS is characterized by an impairment of neuropsychological abilities, frequently associated with behavioral disorders (reduced attention span, hyperkinesis, aggressiveness and difficulty interacting with the environment), hyperactivity, learning disabilities and, in some instances, psychotic regressions. These manifestations strongly correlate with frontal lobe dysfunction (Jasper et al., 1995; Fuster, 1997). These mental and behavioral disorders can persist even after CSWS has ceased. Their severity and persistence seem to be correlated with the duration and severity of ESES (Billard et al., 1990; De Negri, 1994). The goal of evaluation and treatment of CSWS must not necessarily be a seizure-free state, but improvements in seizure control, alertness, mood and behavior. We have already studied and reported prefrontal lobe volumes in a patient with CSWS using three-dimensional (3D) magnetic resonance imaging (MRI) (Kanemura et al., 2009). However, the data cannot be 
generalized to all CSWS cases because the investigation included evaluation of only one case. Many unanswered questions remain with regard to CSWS, such as its clinical significance, pathophysiology and treatment. Further studies are needed to confirm and elaborate on these anatomical observations and extend the systematic study of cognitive, social and moral development, and to clarify outcomes for many children with CSWS.

In the present study, there were three cases with disappearance of the paroxysmal anomalies, yet in these cases there was no improvement of the neuropsychological impairments. By contrast, in the two cases with shorter seizure and paroxysmal anomaly durations, there was remarkable improvement of behavioral disturbances. In several diseases of the central nervous system, conventional MRI has proven to be sensitive for detecting changes over time. Stronger correlations have been found between disability and MR markers such as the quantitative assessment of cerebral atrophy in various brain diseases. On the basis of these previous observations, we serially measured frontal and prefrontal lobes volumes by 3D MRI-based volumetry in children with CSWS and discussed the pathogenesis of ESES-induced brain damage. Finally, we also discussed the role of some prognostic factors such as the duration of CSWS period.

\section{Methods}

\subsection{Subjects}

We studied five patients between 9 and 12 years of age. The criterion for inclusion in the study was the finding of the presence of spike-and-wave discharges in at least $85 \%$ of nonrapid eye movement (REM) sleep, which were verified by two consecutive electroencephalography (EEG) recordings over a period of more than 1 month. All patients underwent EEG recordings while awake and during afternoon sleep. The clinical profiles are summarized in Table 1.

\begin{tabular}{cccccccccc}
\hline Case & $\begin{array}{c}\text { Age } \\
\text { (y) }\end{array}$ & $\begin{array}{c}\text { Age at } \\
\text { seizure } \\
\text { onset } \\
\text { (y) }\end{array}$ & $\begin{array}{c}\text { CSWS } \\
\text { after } \\
\text { seizure } \\
\text { (y) }\end{array}$ & $\begin{array}{c}\text { Duration of } \\
\text { CSWS period } \\
\text { (months })\end{array}$ & $\begin{array}{c}\text { FIQ } \\
\text { (pre) }\end{array}$ & $\begin{array}{c}\text { FIQ } \\
\text { (post) }\end{array}$ & $\begin{array}{c}\text { Behavioral } \\
\text { problems }\end{array}$ & $\begin{array}{c}\text { Seizure } \\
\text { outcome }\end{array}$ & Final drugs \\
1 & 10 & 4 & 2.2 & 14 & 85 & 67 & HA, PSP & none & VPA+CLB \\
2 & 11 & 5 & 1.8 & 19 & 88 & 62 & $\begin{array}{c}\text { PSP, HA, } \\
\text { IA, IP }\end{array}$ 1-3x/month & VPA+ESM \\
3 & 12 & 5 & 2.9 & 21 & 73 & 52 & $\begin{array}{c}\text { PSP, HA, } \\
\text { IP }\end{array}$ & none & VPA+CLB \\
4 & 9 & 3 & 2.1 & 5 & ND & 86 & HA $(+) \rightarrow(-)$ & none & VPA+CLB \\
5 & 11 & 5 & 1.5 & 5 & 89 & 87 & HA $(+) \rightarrow(-)$ & none & VPA+CLB \\
\hline
\end{tabular}

CSWS, epilepsy with continuous spikes and waves during slow sleep; FIQ full intelligence quantity; ND, not done, HA, hyperactivity; PSP, poor school performance; IA, inattention; IP, impulsivity; IQ' (pre), IQ at the appearance of CSWS; IQ (post), IQ at 4 years after the appearance of CSWS; VPA, valporate sodium; CLB, clobazam; ESM, ethosuximide

Table 1. Clinical characteristics of the patients in this study 
All patients were followed up regularly for more than 3 years after the onset of seizures. During the active ESES phase, sleep EEG recordings were performed at least once every 3 months. Subsequently, EEGs were recorded during afternoon sleep once every 2-3 months for more than 1 year after the disappearance of ESES. For each patient we examined familial antecedents for epilepsy/febrile convulsion, personal antecedents, psychomotor development, neurologic examination and cerebral MRI. All patients had normal findings on routine MR studies. All patients have shown behavioral disturbances or cognitive impairments. Two patients, with a CSWS duration of less than 6 months, showed remarkable improvements of behavioral disturbances. By contrast, three patients with a CSWS duration of greater than 1 year presented progressive cognitive and behavioral deteriorations, even after seizures and paroxysmal EEG activities disappeared. Formal IQ testing was carried out in all cases. Informed consent was obtained from the parents. Clinical courses of all patients are outlined briefly below.

\subsubsection{Case 1}

The first patient was a male who presented with complex partial seizures at 4 years of age. The patient was born normally, and his psychomotor development was normal before the onset of seizures. The patient's history of illness and the family history were noncontributory. EEG revealed sharp waves at bilateral centro-temporal regions superimposed on normal background activity. Carbamazepine (CBZ) was started initially. At 6 years of age, he started exhibiting atypical absence seizures. On the EEG, the ESES pattern was revealed (Fig. 1). He became irritable, hyperactive, aggressive and disinhibited, displaying difficulty interacting with his environment. Treatment was changed to using valproate sodium (VPA). However, no improvement of his clinical state was recognized. Clobazam (CLB) was started in addition to VPA, which led to improvement. Eleven months after replacement of antiepileptic drugs (AEDs), the ESES pattern resolved with no further seizures. However, he presented a progressive cognitive and behavioral deterioration up to the present, and IQ dropped from 85 to 67 of total score. The duration of the CSWS period was 14 months.

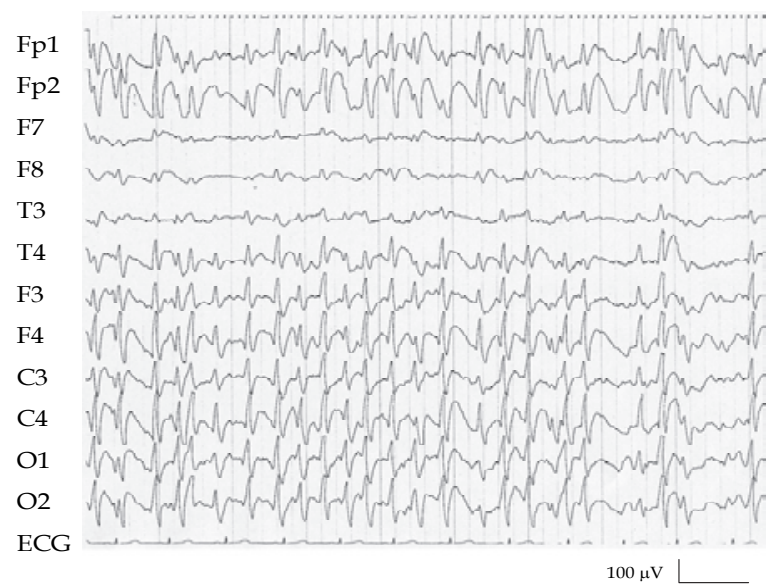

Fig. 1. Electroencephalography (EEG) tracing taken during sleep in case 1. Such patterns occupied $85 \%$ to $90 \%$ of the hours normally given to slow-wave 


\subsubsection{Case 2}

This patient was an 11-year-old male, the second child of healthy parents. He had normal initial psychomotor development. At age 5 years, he started with sporadic, generalized tonic-clonic seizures, which were controlled by VPA. A sleep EEG recording showed focal spike and wave discharges over the right central and temporal leads (C4-T4). At age 7 years, he started with atypical absence seizures. On the EEG, the ESES pattern was revealed. He became hyperactive, aggressive and disinhibited, and exhibited difficulty interacting with his environment. Treatment was changed to using CLB. However, the improvement of his clinical state was not fully recognized. Ethosuximide (ESM) was started in addition to VPA, which led to improvement. The ESES pattern resolved with a reduction in the rate of seizures. However, he presented a progressive cognitive and behavioral deterioration, including poor school performance, hyperactivity, and impulsiveness. The duration of the CSWS period was 19 months.

\subsubsection{Case 3}

This patient was a 12-year-old male. Delayed psychomotor development was recognized before the onset of seizures, but behavioral deterioration, including hyperactivity, was not recognized. At the age of 5 years, he had his first episode of clonic seizures of his right upper-limb. His clinical seizures were controlled by CBZ transiently. At the age of 7 years, he started with atypical absence seizures. On the EEG, the ESES pattern was revealed. He became irritable, hyperactive and aggressive, showing difficulty interacting with the environment. Treatment was changed to using VPA, but improvements to his clinical state were not recognized. Treatment was changed to using VPA with CLB, which led to improvement. The ESES pattern resolved with no further seizures. However, he exhibited a cognitive and behavioral deterioration, including poor school performance, hyperactivity, and impulsiveness. The duration of the CSWS period was 21 months.

\subsubsection{Case 4}

This patient was a 9-year-old male. He had normal initial psychomotor development before the onset of seizures. At the age of 3 years, he had his first episode of clonic seizures of left upper-limb. The EEG showed focal spike and wave discharges in the right frontal and central leads (F4-C4) superimposed on normal background activity. His clinical seizures were transiently controlled by CBZ. At the age of 5 years, he started with atypical absence seizures. On the EEG, the ESES pattern was revealed. He presented behavioral disturbances such as hyperactivity. Treatment was changed to using VPA, yet the improvements to his clinical state were not noted. Treatment was changed to using VPA with CLB, which led to gradual improvement. The ESES pattern resolved with no further seizures. There was considerable improvement of behavioral disturbances. The duration of the CSWS period was 5 months.

\subsubsection{Case 5}

This patient was an 11-year-old female who had normal initial psychomotor development and was described in our previous report (Kanemura et al., 2009). At the age of 5 years, she had her first episode of complex partial seizure. EEG revealed sharp waves at bilateral centro-temporal regions superimposed on normal background activity. Her clinical seizures were transiently controlled by CBZ. At 6 years of age, she started with atypical absence 
seizures. On the EEG, the ESES pattern was revealed. She presented behavioral disturbances such as hyperactivity. Treatment was changed to using VPA. However, improvements to her clinical state were not recognized. Treatment was changed to include VPA and CLB, which led to gradual improvement. The ESES pattern resolved with no further seizures. There was considerable improvement of behavioral disturbances. The duration of the CSWS period was 5 months.

\subsection{Serial 3D-MR volumetric study}

The longitudinal 3D MRI studies were performed six times (at the onset of the ESES pattern, 6 months, 1, 2, 3 and 4 years after the onset of ESES) in all cases.

The control group consisted of 13 age-matched children ranging in age from 5 to 12 years. Clinical indications for MR imaging were suspected speech delay, brain trauma, brain tumor, short stature and migraine, which turned out to be neurologically and / or psychologically insignificant during a 2-4 year follow-up period after this study. All subjects had normal findings on routine MR studies.

All MRI scans were performed on the Siemens 1.5 Tesla by Signa Advantage. The 3D MRI data were acquired by the fast spoiled gradient recalled echo in steady state with three dimensional Fourier transformation. 3D images of the whole brain surface were obtained from the 124 sections using Advantage Windows RP 3D analyzer (Siemens, Wisconsin, MW, U.S.A.). Thereafter, the frontal lobe was delineated and confirmed by our published method (Kanemura et al., 2003). Finally, we measured the frontal and prefrontal lobe volumes by the volume measurement function of Workstation on the 3D images.

\section{Results}

Measured volumes for frontal and prefrontal lobe, and prefrontal to frontal lobe volume ratio are shown in Fig. 2 (A; frontal lobe volume, B; prefrontal lobe volume, C; prefrontal to frontal volume ratio). Frontal and prefrontal lobe volumes revealed growth disturbance in all cases compared with those of normal subjects (Fig. 2A and 2B). In addition, prefrontal to frontal lobe volume ratios increased serially in normal subjects, whereas the ratios stagnated or decreased in all cases of CSWS (Fig. 2C). In cases 4 and 5, with shorter seizure durations and CSWS periods, ratios were soon restored to a more normal growth ratio. On the other hand, growth disturbances of the prefrontal lobes were persistent in cases 1, 2 and 3, which all had longer seizure durations and CSWS periods (Fig. 2C).

\section{Discussion}

Seizure discharge of generalized nonconvulsive status has been postulated to cause neuronal damage. Various childhood epileptic syndromes associated with dramatic activation of the epileptiform activities during slow wave sleep may manifest with progressive psychomotor decline, which cannot be attributed to known metabolic or organic causes. CSWS is the main representative syndrome, which is frequently encountered in pediatric syndromes associated with epilepsy or cognitive and language dysfunction. Nowadays, it is appreciated that CSWS often accompanies epileptic syndromes associated with partial or generalized seizures, occurring during sleep, as well as atypical absences when awake. Thus, the five patients described in this report had clinical features that were consistent with the criteria proposed for CSWS. 
Many CSWS children develop severe cognitive and language deterioration that is unresponsive to medical treatment as the disease progresses (Smith \& Hoeppner, 2003). During the CSWS period, there is the appearance of a further decrease in performance; a marked impairment of IQ, deterioration of language, temporo-spatial disorientation, behavioral changes and, rarely, psychotic features have been described (Tassinari, 1992). Patients with CSWS had lower scores in tests measuring their lexical, morphosyntactic, and pragmatic skills compared to controls (Debiais et al., 2007). Furthermore, language impairment was found to be just as severe in patients in remission as those still in an active phase (Debiais et al., 2007). Paroxysmal anomalies in CSWS may be associated with a disruption of all cognitive functions, with sometimes a greater impairment of logicalstructural intelligence and of infrastructural intelligence, possibly in relation to a previously different intellectual organization (Tassinari et al., 2005).

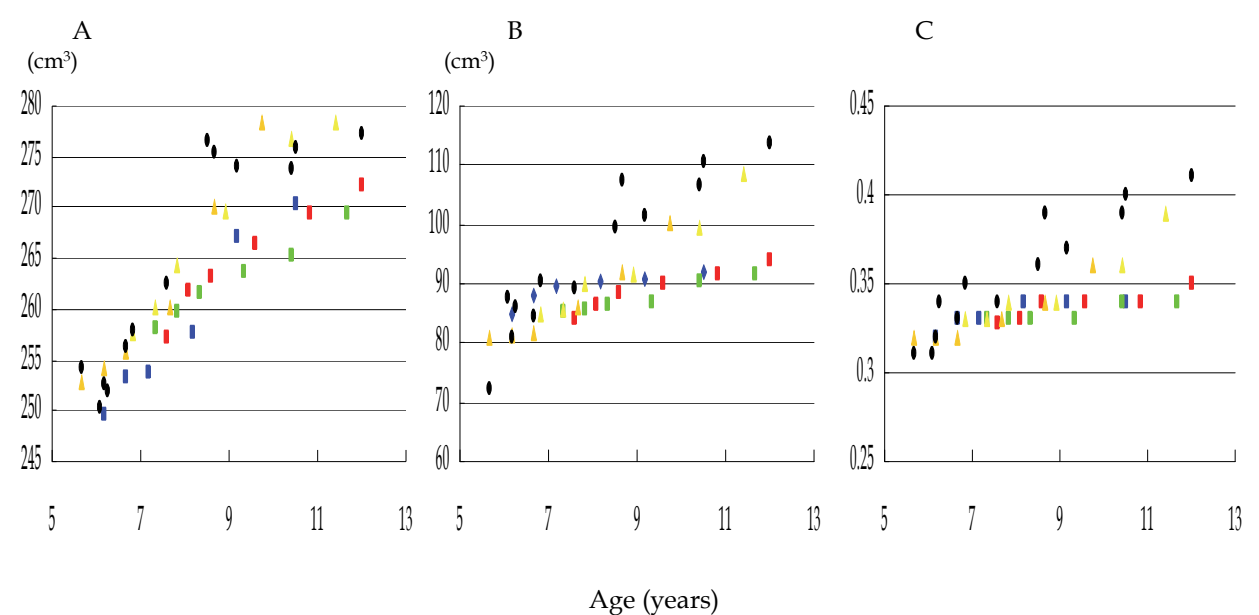

Fig. 2. Volume measurements of five cases with CSWS and normal subjects. Serial changes in frontal lobe volume (A), prefrontal love volume (B), and prefrontal to frontal lobe volume ratio (C). Scatter plots for the case 1 (blue squares), case 2 (green squares), case 3 (red squares), case 4 (gold triangles), case 5 (yellow triangles) and age matched normal subjects (black diamonds). Frontal and prefrontal lobe volumes revealed growth disturbance in all cases compared with normal subjects. In addition, prefrontal to frontal lobe volume ratio increased serially in the normal subjects, whereas its increases are declined in all cases. The case 4 and 5 with shorter seizure duration and CSWS period were soon restored to a more normal growth ratio. On the other hand, growth disturbances of the prefrontal lobes in cases 1,2 and 3 with longer seizure durations and CSWS period were persistent.

Concerning the CSWS-related neuropsychological disturbances, several authors have underlined the parallel, though not perfectly overlapping, course of CSWS and mental and behavioral abnormalities (De Negri et al., 1995). There is a well-documented increased incidence of attention deficit hyperactivity disorder (ADHD) and behavioral disorders, which are likely to be independent of the degree of seizure control (Schubert, 2005). Hyperactivity has been reported in about half of the cases of behavioral and cognitive disturbances. Disturbances of personality with psychotic characteristics have been 
described, as well as a global cognitive regression and impairment of affective development, with aggressiveness and outbursts of rage (Gordon, 1990; Roulet et al., 1991). These disorders are often progressive and insidious with devastating effects on cognition and behavior, although the children generally have few or sometimes no classic seizures. The manifestation of neuropsychological disorders coincided with the onset and disappearance of ESES EEG expression rather than with the outcome of clinical seizures (Morikawa et al., 1992). Abnormal collecting behavior, characterized by increased, indiscriminate acquisition behavior and diminished discarding behavior, will occur following damage to prefrontal regions, but not after damage elsewhere in the brain (Anderson et al., 2005). In LandauKleffner syndrome (LKS) the paroxysmal activity permanently affects the posterior temporal area and results in auditory agnosia and language deficits, whereas in CSWS the frontal lobes are more involved and other cognitive disturbances predominate (Smith \& Polkey, 2008). Thus, epilepsies associated with CSWS in childhood may affect the prefrontal cortex and leave residual mental and behavioral abnormalities as profound and as permanent as the loss of speech in LKS.

MRI is currently the most effective method for detecting gross structural lesions in patients with various brain diseases. There is little question that recent advances in neuroimaging, particularly MRI, have revolutionized the evaluation and management of epilepsy and seizure disorders. Given the possibility that some functional changes may have a structural correlate, MRI could also play a pivotal role in elucidating the mechanisms underlying epileptogenesis. However, neuroradiological abnormalities in patients with CSWS can be found only in 30-60 percent of cases (Galanopoulou et al., 2000). In pure forms of this syndrome, no gross structural lesions are detected by CT or MRI scans (Beaumanoir, 1992). On the other hand, in accordance with histopathologic examinations, the development of permanent neurological impairment may be associated with progressive brain atrophy (Trapp et al., 1998). Within these analyses, quantitative MRI investigations have been performed to evaluate neurological abnormalities in children with epilepsy. Hippocampal volumes are large in patients with prolonged febrile convulsion when compared with controls by quantitative hippocampal volumetry (Scott et al., 2002). Thus, quantification of brain volume is a useful way to characterize the normal growth and abnormal development in patients with epilepsy. Furthermore, prospective and serial analysis with brain volumetry may support the pathogenesis of CSWS-induced brain damage.

All cases presented in this report revealed growth disturbance of the frontal lobe, especially the prefrontal lobe in quantitative volumetric analysis. Volumetric analysis of the brain may predict function in corresponding regions. Our results showed enhanced vulnerability of prefrontal cortex during early development coincident with CSWS. In our findings, the frontal and prefrontal lobe volumes, especially the prefrontal to frontal lobe volume ratio, showed growth disturbance during the CSWS period, and even after paroxysmal anomalies in CSWS have ceased. Our results suggest that children with CSWS may have frontal lobe dysfunctions even if paroxysmal anomalies had ceased or further afebrile seizures had not appeared. The temporal development of the frontal and prefrontal lobe volumes in longitudinal studies of CSWS patients is still unclear. To the best of our knowledge, no attempt has been made to measure individual cerebral lobes in patients with CSWS. Our study therefore may be the first to evaluate growth retardation of the frontal and prefrontal lobes in patients with CSWS.

Regardless of the prior cognitive status and development, the appearance of CSWS is associated with emergence of new cognitive and behavioral abnormalities (Tassinari et al., 2005). A cluster of problems that appear to be more common in children with epilepsy is the 
disruptive behavioral disorder group: ADHD, oppositional defiant disorder, and conduct disorder. ADHD is described in approximately two thirds of the reported cases (Boel \& Casaer, 1989; Guerrini et al., 1998). Hyperactivity and oppositional behaviors are highly associated. Aggressiveness, deficits in relatedness and inhibition, bizarre behavior, emotional lability and psychotic behavior have also been described (Roulet-Perez et al., 1993; Kyllerman et al., 1996). These manifestations may be correlated with frontal lobe dysfunction (Jasper et al., 1995; Fuster, 1997). Thus, these symptoms constitute frontal lobe syndrome (Roulet-Perez et al., 1993). In some of CSWS children, the seemingly generalized epileptiform abnormality represents true secondary bilateral synchrony (Morrell et al., 1995). The most common location for a lesion to produce secondary bilateral synchrony is in the frontocentral region, followed by the temporal and parietal cortex (Blume \& Pillay, 1985; Wasterlain et al., 1993). Secondary bilateral synchrony originated in the frontal lobe in nearly half of patients, significantly more often than the incidence of frontal spikes among controls (Blume \& Pillay, 1985). Frontal foci may easily elicit sustained bisynchronous discharges which often spread diffusely. CSWS, which develops within a broader age range, with multiple focal or predominantly frontal paroxysmal anomalies, may be comprehensively associated with more generalized neuropsychological and/or mental regression. However, paroxysmal anomalies in our patients were not always predominant in frontal regions. Blume et al. reported the presence of more than one spike focus in $96 \%$ of patients and three or more foci in $77 \%$ suggested that secondary bilateral synchrony results from a complex interaction of multiple potentially epileptogenic regions (Blume \& Pillay, 1985). A complex interaction of multiple cortical epileptiform discharges may act through thalamic and callosal connections to create bisynchronous epileptiform paroxysms. Independent of etiology and individual area of initial epileptic activity, patients with CSWS may be characterized by a consistent specific neuronal network of activation. In a recent study, the activation in the perisylvian/prefrontal network was associated with both activation in the thalamocortical network and deactivation in the default mode network (Siniatchkin et al., 2010). Our results and these findings suggest that children with CSWS may have abnormalities in the frontal lobe even if the epileptic focus is not frontal.

Long-term prognosis for the seizure disorder is good, with less than $20 \%$ of patients suffering from persistent, usually rare, seizures (Bureau, 1995). However, the long-term prognosis for neuropsychological consequences is not nearly as good as was once thought. Therefore, in considering outcomes for children with CSWS, it is necessary to consider the control of seizures on one hand and the incidence of neurological impairments, either transitory or persistent, on the other. The duration of epilepsy seems to be a significant prognostic factor. In our study, prefrontal growth made rapid recovery in patients with a shorter duration of CSWS. The CSWS duration in three of the patients with poor outcomes was longer than in those who had better prognosis. This finding suggests that seizure and the duration of paroxysmal anomalies may be associated with prefrontal lobe growth, which is associated with neuropsychological problems. Our results are agreement with the findings that CSWS patients with the longest persistence of spike-and-wave discharges over time are most affected (Smith \& Polkey, 2008).

The pathophysiology of CSWS is complex and far from being elucidated. The relation between the density of paroxysmal anomalies and neuropsychological regression is based on clinical findings, notably, the parallel between paroxysmal anomalies duration and ultimate neuropsychological outcome, as well as between the neuropsychological disturbances and the location of the interictal epileptic focus (Tassinari et al., 2005; De Negri, 1994; Morikawa et al., 1992). In addition, the most convincing theory maintains that focal 
epileptic activity produces a disturbance in the maturation of cortical zones, mainly in the associative areas (Praline et al., 2003). Nonconvulsive status epilepticus (SE) in adult animals leads to widespread neuronal necrosis in vulnerable regions (Wasterlain et al., 1993). Furthermore, inhibition of brain growth, DNA and protein synthesis, and myelin formation and of synaptogenesis may lead to altered brain development (Wasterlain et al., 1993). Rat pups as young as 2 weeks old demonstrate seizure-induced elevation in serum neuronspecific enolase accompanied by histological evidence of damage as a result of status epilepticus (Sankar et al., 1997). Furthermore, in our previous study, a longer active seizure period as frequent spike-waves coupled with the occurrence of frequent seizures in patients with benign childhood epilepsy with centro-temporal spikes may be associated with prefrontal lobe growth disturbance (Kanemura et al., 2011). Our results are in agreement with these findings. Patients with CSWS require regular and prolonged clinical and EEG follow-up.

The same disorder that causes seizures may also have the potential to limit intellectual development in many patients. People with learning disabilities represent an important subgroup within the population of patients with epilepsy. On the other hand, the interface between epilepsy and behavior disorders has a long and checkered history. The coexistence of intellectual deficits and behavioral abnormalities may substantially interfere with the medical assessment of seizures. If the relationship between the occurrence of paroxysmal anomalies and the onset of a neuropsychological deterioration is accepted, an aggressive therapy can be justified (Tassinari et al., 2005). This may require modification of antiepileptic therapy, psychosocial intervention, or the use of psychotropic medication. Our study demonstrated that clinical seizures and EEG discharges responded well to a benzodiazepine such as CLB when combined with VPA in four of 5 patients. The study by Liu et al. has demonstrated a dramatic improvement in the clinical findings and occurrence of the CSWS phenomenon with administration of low-dose benzodiazepines in a cohort of 18 children with language, behavioral, and neuropsychologic deterioration (Liu \& Wong, 2000). In agreement with Tassinari et al. (Tassinari et al., 2005), benzodiazepines in combination with VPA seem to be the most effective treatment at present. However, the patients in our study have exhibited mental and behavioral disorders even after the CSWS period has ceased. Inutsuka et al. reported that the effects of short cycles of high-dose diazepam and ACTH-Z (tetracosactide Zn) therapy were temporary at best (Inutsuka et al., 2006). The potential for early reversibility of clinical and EEG abnormalities with benzodiazepine, however, will improve the outcomes for children with CSWS. Further investigations may clarify whether deficits of cognition and behavior are transient or permanent. In addition, the sample in this study is too small to discuss the pathophysiology and outcome of CSWS. Further studies are needed to confirm and elaborate on these anatomical observations by 3-D MRI based volumetry to extend the systematic study of cognitive, social, and moral development, and to predict the likely outcome of CSWS for many children with CSWS.

\section{Conclusion}

This study revealed the frontal and prefrontal lobe volumes, and the prefrontal to frontal lobe volume ratio in particular showed growth disturbances during the CSWS period, and even after CSWS had ceased. The duration of symptoms such as seizure and paroxysmal anomalies in the patients with poor outcomes was longer than in those who had better prognosis. These findings suggested that the durations of seizure and paroxysmal anomalies may be associated with prefrontal lobe growth, which relates to neuropsychological 
problems. These findings in our study provide further support for the integral involvement of the prefrontal cortex in CSWS.

\section{Acknowledgment}

This research was supported in part by Grants-in-Aid for Scientific Reasearch C (22591124 and 22591123).

\section{References}

Anderson, S.W., Damasio, H., \& Damasio, A.R. (2005). A neural basis for collecting behaviour in humans. Brain, Vol. 128, No. 1, pp. 201-212, 0006-8950

Beaumanoir, A. (1992). The Landau-Kleffner syndrome, In: Epileptic syndromes in infancy, childhood and adolescence. 2nd ed, Roger, J., Bureau, M., Dravet, C., Dreifuss, FE., Perret, A., \& Wolf, P. (Ed.), pp. 231-243, John Libbey, 086196320 2, London

Billard, C., Autret, A., Lucas, B., Degiovanni, E., Gillet, P., Santini, J.J., \& de Toffol, B. (1990). Are frequent spike-waves during non-REM sleep in relation with an acquired neuropsychological deficit in epileptic children? Neurophysiologie Clinique, Vol. 20, No. 6, pp. 439-453, 0987-7053

Blume, W.T. \& Pillay, N. (1985). Electrographic and clinical correlates of secondary bilateral synchrony. Epilepsia, Vol. 26, No. 6, pp. 636-641, 0013-9580

Boel, M. \& Casaer, P. (1989). Continuous spikes and waves during slow sleep: a 30 months follow-up study of neuropsychological recovery and EEG findings. Neuropediatrics, Vol. 20, No. 3, pp. 176-180, 0174-304X

Debiais S.; Tuller L.; Barthez MA.; Monjauze C.; Khomsi A.; Praline J.; de Toffol B.; Autret A.; Barthelemy C. \& Hommet C. (2007) Epilepsy and language development: the continuous spike-waves during slow sleep syndrome. Epilepsia, Vol. 48, No. 6, pp. 1104-1110, 0013-9580

De Negri M. (1994) Electrical status epilepticus in childhood: neuropsychological impairment and therapeutic management. Developmental Medicine $\mathcal{E}$ Child Neurology, Vol.36, No. 2, pp. 183-186, 0012-1622

De Negri M.; Baglietto MG.; Battaglia FM.; Gaggero R.; Pessagno A. \& Recanati L. (1995) Treatment of electrical status epilepticus by short diazepam (DZP) cycles after DZP rectal bolus test. Brain \& Development, Vol. 17, No. 5, pp. 330-333, 0387-7604

Fuster, J.M. (1997). The Prefrontal Cortex: Anatomy, Physiology, and Neuropsychology of the Frontal Lobe (3 ${ }^{\text {rd }}$ ed.), Lippincott-Raven, 0-397-51849-9, Philadelphia

Galanopoulou AS.; Bojko A.; Lado F. \& Moshe SL. (2000) The spectrum of neuropsychiatric abnormalities associated with electrical status epilepticus in sleep. Brain $\mathcal{E}$ Development, Vol. 22, No. 5, pp. 279-295, 0387-7604

Gordon N. (1990) Acquired aphasia epilepsia in childhood: the Landau-Kleffner syndrome. Developmetal Medicine E Child Neurology, Vol. 32, No. 3, pp. 270-274, 0012-1622

Guerrini R.; Genton P.; Bureau M.; Parmeggiani A.; Salas-Puig X.; Santucci M.; Bonanni P.; Ambrosetto G. \& Dravet C. (1998) Multilobar polymicrogyria, intractable drop attack seizure, and sleep-related electrical status epilepticus. Neurology, Vol. 51, No. 2, pp. 504-512, 0028-3878 
Inutsuka M.; Kobayashi K.; Oka M.; Hattori J. \& Ohtsuka Y. (2006) Treatment of epilepsy with electrical status epileptics during slow sleep and its related disorders. Brain $\mathcal{E}$ Development, Vol. 28, No. 5, pp. 281-286, 0387-7604

Jasper, H.H., Riggio, S., \& Goldman-Rakic, P.S. (Eds.). (1995). Epilepsy and the Functional Anatomy of the Frontal Lobe: Advances in Neurology, Raven Press, 0-7817-0229-1, New York

Kanemura H, Aihara M, Aoki S, Araki T, Nakazawa S. (2003) Development of the prefrontal lobe in infants and children: a three-dimensional magnetic resonance volumetric study. Brain \& Development, Vol. 25, No. 3, pp. 195-199, 0387-7604

Kanemura H.; Hata S.; Aoyagi K.; Sugita K. \& Aihara M. (2011) Serial changes of prefrontal lobe growth in the patients with benign childhood epilepsy with centrotemporal spikes presenting with cognitive impairments/behavioral problems. Brain $\mathcal{E}$ Development, Vol. 33, No. 2, pp. 106-113, 0387-7604

Kanemura H, Sugita K, Aihara M. (2009) Prefrontal lobe growth in a patient with continuous spike-waves during slow sleep. Neuropediatrics, Vol. 40, No. 4, pp. 192194, 0174-304X

Kyllerman M.; Nyden A.; Praquin N.; Rasmussen P.; Wetterquist A-K. \& Hedstrom A. (1996) Transient psychosis in a girl with epilepsy and continuous spikes and waves during slow sleep (CSWS). European Child \& Adolescent Psychiatry, Vol. 5, No. 4, pp. 216-221, 1018-8827

Liu XY. \& Wong V. (2000) Spectrum of epileptic syndromes with electrical status epilepticus during sleep in children. Pediatric Neurology, Vol. 22, No. 5, pp. 371-379, 0887-8994

Morikawa T.; Seino M. \& Yagi K. (1992) Long-term outcome of four children with continuous spike-waves during sleep, In: Epileptic syndromes in infancy, childhood and adolescence. 2nd ed, Roger J.; Bureau M.; Dravet CH.; DreifussFE.; Perret A. \& Wolf P. (Ed), pp. 257-266, John Libbey, 086196320 2, London.

Morrell F.; Whisler WW.; Smith MC.; Hoeppner TJ.; de Toledo-Morrell L.; Pierre-Louis SJ.; Kanner AM.; Buelow JM.; Ristanovic R.; Chez M. \& Hasegwa H. (1995) LandauKleffner syndrome: treatment with subpial intracortical transaction. Brain, Vol. 118, No. 6, pp. 1529-1546, 0006-8950

Noeker M.; Haverkamp-Krois A. \& Haverkamp F. (2005) Development of mental health dysfunction in childhood epilepsy. Brain E Development, Vol.27, No.1, pp.5-16, 0387-7604

Praline J.; Hommet C.; Barthez MA.; Brault F.; Perrier D.; Passage GD.; Lucas B.; Bonnard C.; Toffol BD. \& Autret A. (2003) Outcome at adulthood of the continuous spike-waves during slow sleep and Landau-Kleffner syndrome. Epilepsia, Vol. 44, No. 11, pp. 1434-1440, 0013-9580

Roulet E.; Deonna T.; Gaillard F.; Peter-Favre C. \& Despland PA. (1991) Acquired aphasia; dementia and behavior disorder with epilepsy and continuous spike and waves during sleep in a child. Epilepsia, Vol. 32, No. 4, pp. 495-503, 0013-9580

Roulet-Perez E.; Davidoff V.; Despland PA. \& Deonna T. (1993) Mental and behavioral deterioration of children with epilepsy and CSWS: acquired epileptic frontal syndrome. Developmental Medicine E Child Neurology, Vol. 35, No. 8, pp. 661-674, 0012-1622 
Sankar R.; Shin DH. \& Wasterlain CG. (1997) Serum neuron-specific enolase is a marker for neuronal damage following status epilepticus in the rat. Epilepsy Research, Vol. 28, No. 2, pp. 129-136, 0920-1211

Schubert R. (2005) Attention deficit disorder and epilepsy. Pediatric Neurology, Vol. 32, No. 1, pp. 1-10, 0887-8994

Scott RC.; Gadian DG.; King MD.; Chong WK.; Cox TC.; Neville BG. \& Connelly A. (2002) Magnetic resonance imaging findings within 5 days of status epilepticus in childhood. Brain, Vol. 125, Vol. 9, pp. 1951-1959, 0006-8950

Siniatchkin M.; Groening K.; Moehring J.; Moeller F.; Boor R.; Brodbeck V.; Michel CM.; Rodionov R.; Lemieux L. \& Stephani U. (2010) Neuronal networks in children with continuous spikes and waves during slow sleep. Brain, Vol. 133, No. , pp.2798-2813, 0006-8950

Smith MC. \& Hoeppner TJ. (2003) Epileptic encephalopathies of late childhood: LandauKleffner syndrome and the syndrome of continuous spike and wave during slow wave sleep. Journal of Clinnical Neurophysiology, Vol. 20, No. 6, pp. 462-472, 07360258

Smith MC. \& Polkey CE. (2008) Landau-Kleffner syndrome and CSWS. In: Epilepsy. A comprehensive textbook. 2nd ed, Engel Jr. J. \& Pedley TA.(Ed), pp. 2429-2438, Lippincott Williams \& Wilkins, 978-0-7817-5777-5, Philadelphia.

Tassinari CA.; Rubboli G.; Volpi L.; Billard C. \& Bureau M. (2005) Electrical status epilepticus during slow sleep (ESES or CSWS) including acquired epileptic aphasia (Landau-Kleffner syndrome). In: Epileptic syndromes in infancy, childhood and adolescence. 4th ed, Roger J.; Bureau M., Dravet C.; Genton P.; Tassinari CA. \& Wolf P. (Ed), pp. 295-314, John Libbey, 2-74200 575-7, London.

Trapp BD.; Peterson J.; Ransohoff RM.; Rudick R.; Mork S. \& Bo L. (1998) Axonal transaction in the lesions of multiple sclerosis. New England Journal of Medicine, Vol. 338, No. 5, pp. 278-285, 0028-4793

Wasterlain CG.; Fujikawa DG.; Penix L. \& Sankar R. (1993) Pathophysiological mechanisms of brain damage from status epilepticus. Epilepsia, Vol. 34 (Suppl. 1), pp. S37-53, 0013-9580 


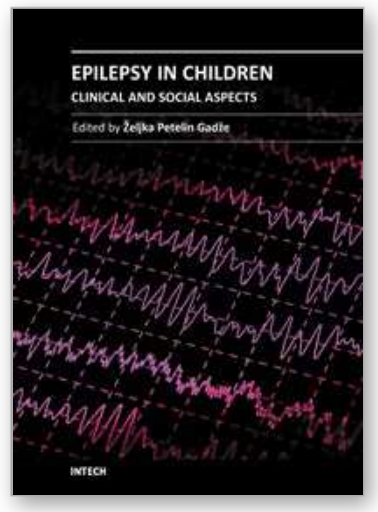

\author{
Epilepsy in Children - Clinical and Social Aspects \\ Edited by Dr. Zeljka Petelin Gadze
}

ISBN 978-953-307-681-2

Hard cover, 234 pages

Publisher InTech

Published online 15, September, 2011

Published in print edition September, 2011

Epilepsy is a neurological condition that accompanies mankind probably since its inception. About 400 years before Christ, the disease was already known by Hippocrates, who wrote the book â€œOn The Sacred Diseaseâ€. Classically, epilepsy has been defined as a chronic condition characterized by an enduring propensity to generate seizures, which are paroxysmal occurring episodes of abnormal excessive or synchronous neuronal activity in the brain. Out of all brain disorders, epilepsy is the one that offers a unique opportunity to understand normal brain functions as derived from excessive dysfunction of neuronal circuits, because the symptoms of epileptic seizures are not the result of usual loss of function that accompanies many disease that affect the brain. I am therefore extremely honoured to present this book. The 15 very interesting chapters of the book cover various fields in epileptology â $€$ " they encompass the etiology and pathogenesis of the disease, clinical presentation with special attention to the epileptic syndromes of childhood, principles of medical management, surgical approaches, as well as social aspects of the disease.

\title{
How to reference
}

In order to correctly reference this scholarly work, feel free to copy and paste the following:

Hideaki Kanemura and Masao Aihara (2011). Sequential Prefrontal Lobe Volume Changes in Epileptic Patients with Continuous Spikes and Waves During Slow Sleep, Epilepsy in Children - Clinical and Social Aspects, Dr. Zeljka Petelin Gadze (Ed.), ISBN: 978-953-307-681-2, InTech, Available from: http://www.intechopen.com/books/epilepsy-in-children-clinical-and-social-aspects/sequential-prefrontal-lobevolume-changes-in-epileptic-patients-with-continuous-spikes-and-waves-dur

\section{INTECH}

open science | open minds

\section{InTech Europe}

University Campus STeP Ri

Slavka Krautzeka 83/A

51000 Rijeka, Croatia

Phone: +385 (51) 770447

Fax: +385 (51) 686166

www.intechopen.com

\section{InTech China}

Unit 405, Office Block, Hotel Equatorial Shanghai

No.65, Yan An Road (West), Shanghai, 200040, China 中国上海市延安西路65号上海国际贵都大饭店办公楼 405 单元

Phone: +86-21-62489820

Fax: +86-21-62489821 
(C) 2011 The Author(s). Licensee IntechOpen. This chapter is distributed under the terms of the Creative Commons Attribution-NonCommercialShareAlike-3.0 License, which permits use, distribution and reproduction for non-commercial purposes, provided the original is properly cited and derivative works building on this content are distributed under the same license. 